\title{
The impacts of contact force, power and application time on ablation effect indicated by serial measurements of impedance drop in both conventional and high-power short-duration ablation settings of atrial fibrillation
}

\author{
Li-Bin Shi $^{1,2} \cdot$ Yu-Chuan Wang ${ }^{2,3} \cdot$ Song-Yun Chu ${ }^{2,3} \cdot$ Alessandro De Bortoli $^{4} \cdot$ Peter Schuster $^{1,2} \cdot$ Eivind Solheim $^{2}$. \\ Jian Chen ${ }^{1,2}$ (D)
}

Received: 31 January 2021 / Accepted: 5 April 2021 / Published online: 23 April 2021

(C) The Author(s) 2021

\begin{abstract}
s
Background This study aimed to clarify the interrelationship and additive effects of contact force (CF), power and application time in both conventional and high-power short-duration (HPSD) settings.

Methods Among 38 patients with paroxysmal atrial fibrillation who underwent first-time pulmonary vein isolation, 787 ablation points were collected at the beginning of the procedure at separate sites. Energy was applied for $60 \mathrm{~s}$ under power outputs of 25 , 30 or $35 \mathrm{~W}$ (conventional group), or $10 \mathrm{~s}$ when using $50 \mathrm{~W}$ (HPSD group). An impedance drop (ID) of $10 \Omega$ was regarded as a marker of adequate lesion formation.

Results ID $\geq 10 \Omega$ could not be achieved with $\mathrm{CF}<5 \mathrm{~g}$ under any power setting. With $\mathrm{CF} \geq 5 \mathrm{~g}$, ID could be enhanced by increasing power output or prolonging ablation time. ID for 30 and $35 \mathrm{~W}$ was greater than for $25 \mathrm{~W}(p<0.05)$. Ablation with $35 \mathrm{~W}$ resulted in greater ID than with $30 \mathrm{~W}$ only when CF of 10-20 g was applied for $20-40 \mathrm{~s}(p<0.05)$. Under the same power output, ID increased with CF level at different time points. The higher the CF, the shorter the time needed to reach ID of $10 \Omega$ and maximal ID. ID correlated well with ablation index under each power, except for lower ID values at $25 \mathrm{~W}$. ID with $50 \mathrm{~W}$ for $10 \mathrm{~s}$ was equivalent to that with $25 \mathrm{~W}$ for $40 \mathrm{~s}$, but lower than that with $30 \mathrm{~W}$ for $40 \mathrm{~s}$ or $35 \mathrm{~W}$ for $30 \mathrm{~s}$.

Conclusions $\mathrm{CF}$ of at least $5 \mathrm{~g}$ is required for adequate ablation effect. With $\mathrm{CF} \geq 5 \mathrm{~g}$, CF, power output, and ablation time can compensate for each other. Time to reach maximal ablation effect can be shortened by increasing CF or power. The effect of HPSD ablation with $50 \mathrm{~W}$ for $10 \mathrm{~s}$ is equivalent to conventional ablation with $25 \mathrm{~W}$ for $40 \mathrm{~s}$ and $30-35 \mathrm{~W}$ for $20-30 \mathrm{~s}$ in terms of ID.
\end{abstract}

Keywords Pulmonary vein isolation $\cdot$ Contact force $\cdot$ Power $\cdot$ Ablation index $\cdot$ High-power short-duration

\section{Introduction}

Radiofrequency (RF) ablation targeting ectopic atrial activities originating from the pulmonary veins (PV) has emerged

Li-Bin Shi and Yu-Chuan Wang contributed equally to this work.

Jian Chen

jian.chen@med.uib.no

1 Department of Clinical Science, University of Bergen, Bergen, Norway

2 Department of Heart Disease, Haukeland University Hospital, N-5021 Bergen, Norway

3 Peking University First Hospital, Beijing, China

4 Department of Cardiology, Oslo University Hospital, Rikshospitalet, Oslo, Norway as a standard approach for treating atrial fibrillation (AF) [1]. Electrical PV isolation is unanimously regarded as a cornerstone for both paroxysmal and persistent AF ablation [2, 3]. However, achieving durable PV isolation remains challenging during AF ablation, and PV electrical reconnection is frequently observed after AF recurrence, even after employing a contact-force sensing catheter [4-6].

Animal studies using both irrigated and non-irrigated ablation catheters [7-10] have shown a positive correlation between catheter-tip-tissue contact force (CF) and lesion dimensions. Although several observational studies found improvement of clinical outcomes using CF-sensing catheters, further randomized controlled studies did not confirm these initial findings [11]. Other controllable parameters, such as power and application time, also have a critical impact on ablation effectiveness. During low or standard power and long duration ablation, the power is conventionally set at $25-40 \mathrm{~W}$ for a 
duration of 20-60 s. Ablation index (AI), which integrates CF, ablation time, and power in a weighted formula, has been employed as a lesion-related indicator for guiding the ablation procedure. However, the interaction of the controllable parameters and the contribution of each to ablation efficacy have not been clearly elucidated. Recently, a new ablation strategy using high-power and short-duration (HPSD) has emerged as an option for PV isolation. The differences of efficacy between HPSD and conventional ablation settings in clinical practice though have not been demonstrated.

This study aimed to clarify the contribution of CF, power, and application duration and their interrelationship for making an adequate lesion based upon impedance drop as a surrogate for lesion formation and to compare various settings of power, contact force, and ablation duration with regard to ablation effect.

\section{Methods}

We enrolled in this study 38 patients ( 24 men, mean age 65.4 \pm 8.9 years) who underwent their first RF ablation procedure (PV isolation) for symptomatic paroxysmal AF. This study was approved by the Ethics Committee of Western Norway. All patients provided informed consent.

The ablation procedure performed at our institution has been previously described $[12,13]$. Particular to this study, we performed a single transseptal puncture through which both ablation and circular mapping catheters were advanced into the left atrium. We carried out the procedure without the assistance of a dedicated long sheath for the ablation catheter. PV isolation was performed in all patients by ablating circumferentially at the PV antrum. To avoid mutual effects of two RF applications and the impact of the pre-existing scar issues, we identified and enrolled the ablation points in sinus rhythm at separate sites of the PVs (distance $>1 \mathrm{~cm}$, local electrogram amplitude $\geq 2 \mathrm{mV}$ ) before circumferential ablation was performed. Ablations with visually evident displacement of the ablation catheter, stream popping, or overheating with a sudden significant impedance increase were excluded from the analysis. A 3.5-mm-tip CF-sensing irrigated ablation catheter (Navistar ThermoCool SmartTouch $^{\mathrm{TM}}$, Biosense Webster, Diamond Bar, CA, USA) was employed in all the procedures. In the conventional group, $\mathrm{RF}$ energy was delivered in a temperature-controlled mode with a cut-off of $50{ }^{\circ} \mathrm{C}$ at a cooling rate of $2-20 \mathrm{~mL} / \mathrm{min}$. An application time of $60 \mathrm{~s}$ with power of 25,30 or $35 \mathrm{~W}$ was used, respectively. In the HPSD group, energy was delivered in a power-controlled mode with a cooling rate of $2-30 \mathrm{~mL} / \mathrm{min}$ and power of $50 \mathrm{~W}$ applied for $10 \mathrm{~s}$.

An electroanatomic mapping system (Carto 3, Biosense Webster, Diamond Bar, CA, USA) was used and the Visitag module was activated during the procedure. Real-time CF, impedance, temperature and energy delivered were automatically updated and recorded every $20 \mathrm{~ms}$ and analyzed off-line. AI was calculated with a customized formula of $\mathrm{AI}=$ $\left(k \times \int_{0}^{T} C F^{\mathrm{a}}(t) P^{\mathrm{b}}(t) d t\right)^{\mathrm{c}}$ by the system [14]. Impedance drop (ID) was used as the surrogate for assessment of ablation efficacy as correlation between IDs and lesion dimensions has been shown in previous studies $[7,9,13,15]$. ID was defined as the difference between the impedance at a certain time and the baseline value. The maximum ID (MaxID) for each point represented the difference between the minimum impedance value and the impedance at baseline. Considering the variability in impedance between patients, we also calculated the maximum ID percentage (MaxID\%), which was expressed by MaxID/impedance at baseline. During an application, $\mathrm{ID} \geq 10 \Omega$ was regarded as an adequate lesion formation $[13,16,17]$.

\subsection{Statistical analysis}

Continuous variables were presented as mean \pm standard deviation if normally distributed; median and interquartile ranges (IQR) were used if the data were skewed according to the Shapiro-Wilk test. For comparison between groups, the analysis of variance (ANOVA) and post hoc test according to the method of Tukey's honestly significant differences were performed. Categorical values were presented as percentages and analysed by using chi-square test or Fischer's exact test as appropriate. The correlation among continuous variables was tested using Spearman's rho coefficient. Statistical analysis was performed with SPSS version 24 (IBM, USA). A $p$ value of $<0.05$ was considered statistically significant.

\section{Results}

A total of 787 qualified points from 38 patients (median 20 [IQR 17-22] per patient) were included in the analysis. No major complications were observed during and after the procedures. Using temperature-control mode, target power was reached after $4 \mathrm{~s}$, while it took only $1 \mathrm{~s}$ for HPSD ablation with power-control mode. The mean CF ranged from 1.8 to $38.0 \mathrm{~g}$ among all applications. Four sub-groups according to mean $\mathrm{CF}$ value under each power setting $(25,30,35$ and $50 \mathrm{~W})$ were stratified for analysis. The distribution of application points grouped for different CF level and power setting is presented in Table 1. The mean CF was $3.8 \pm 0.8$ vs. $3.8 \pm 0.5 \mathrm{~g}$ in group $\mathrm{CF}<5 \mathrm{~g}, 7.6 \pm 1.4$ vs. $7.0 \pm$ $1.4 \mathrm{~g}$ in group CF $5-10 \mathrm{~g}, 14.2 \pm 2.8$ vs. $13.5 \pm 2.7 \mathrm{~g}$ in group CF $10-20 \mathrm{~g}$ and $25.5 \pm 4.5$ vs. $25.9 \pm 4.7 \mathrm{~g}$ in group $\mathrm{CF} \geq 20 \mathrm{~g}$ (conventional vs. HPSD, $p>0.05$ ). There was no difference regarding mean $\mathrm{CF}$ among different conventional power settings within the same CF level $(p>0.05)$.

The IDs recorded every $10 \mathrm{~s}$ under different power settings at different $\mathrm{CF}$ levels are shown in Fig. 1. We found a strong 
Table 1 Number of applications at different levels of power and contact force and distribution of points reaching an impedance drop of $10 \Omega$ (number and percentage in parenthesis)

\begin{tabular}{|c|c|c|c|c|c|c|}
\hline & & \multicolumn{5}{|c|}{ Mean contact force } \\
\hline & & $\mathrm{CF}<5 \mathrm{~g}$ & CF $5-10 \mathrm{~g}$ & CF $10-20 \mathrm{~g}$ & $\mathrm{CF} \geq 20 \mathrm{~g}$ & Total \\
\hline \multirow{4}{*}{ Power } & $25 \mathrm{~W}$ & $31(7,22.6 \%)$ & $53(25,47.2 \%)$ & $44(35,79.5 \%)$ & $13(13,100 \%)$ & $141(80,56.7 \%)$ \\
\hline & $30 \mathrm{~W}$ & $16(5,31.3 \%)$ & $55(42,76.4 \%)$ & $55(49,89.1 \%)$ & $14(14,100 \%)$ & $140(110,78.6 \%)$ \\
\hline & $35 \mathrm{~W}$ & $22(10,45.5 \%)$ & $60(45,75.0 \%)$ & $44(44,100 \%)$ & $12(12,100 \%)$ & $138(111,80.4 \%)$ \\
\hline & $50 \mathrm{~W}$ & $16(2,12.5 \%)$ & $157(78,49.7 \%)$ & $157(114,72.6 \%)$ & $38(32,84.2 \%)$ & $368(226,61.4 \%)$ \\
\hline Total & & $85(24,28.2 \%)$ & $325(190,58.5 \%)$ & $300(242,80.7 \%)$ & $77(71,92.2 \%)$ & $787(527,67.0 \%$ \\
\hline
\end{tabular}

$C F$ contact force

linear correlation $(\rho=0.978, P<0.0001)$ between MaxID and MaxID\%, which suggested that individual variability in impedance had little effect on the interpretation of our results. MaxID over $10 \Omega$ was reached in 301 out of 419 (71.8\%) ablation points in the conventional group and 226 out of 368 $(61.4 \%)$ points in the HPSD group $(p<0.01)$. The proportion of ablation points in which ID reached $10 \Omega$ is presented in Table 1. Among the conventional subgroups, a higher power and $\mathrm{CF}$ was observed in the points with MaxID $\geq 10 \Omega$ compared with those $<10 \Omega$.

Changes of $\mathrm{CF}$, power and application time individually affected ID and compensated for each other in certain circumstances.

(1) Effect of prolonging application time: The effect of prolonging application time was dependent on the underlying CF and power level. With $\mathrm{CF}<5 \mathrm{~g}$, ID seldom reached $10 \Omega$ within $60 \mathrm{~s}$ regardless of the power output. This was also the case for CF 5-10 g and $25 \mathrm{~W}$. For CF levels beyond 5-10 g, ID increased with prolonged application under all power settings (Fig. 1). However, ablation efficacy extended marginally after 20-30 s ( $p$ $>0.05$, compared to later time points, Fig. 1, Table 2).

(2) Effect of increasing CF: It was observed for a given application time and power level $(25,30$ and $35 \mathrm{~W})$ that ID increased with higher CF (Fig. 1). As shown in Table 2, the time to reach ID $\geq 10 \Omega$ and maxID tended to be shorter with increasing CF levels. A CF $\geq 20 \mathrm{~g}$ led to an ID $\geq 10 \Omega$ within $10 \mathrm{~s}$ in all power settings (Fig. 1).

(3) Effect of increasing power (Fig. 1): As abovementioned, increasing power did not enlarge ID when $\mathrm{CF}<5 \mathrm{~g}$. With $C F \geq 5 \mathrm{~g}$, ID under the power of 30 and $35 \mathrm{~W}$ were significantly higher than under $25 \mathrm{~W}(P<0.01)$. ID under 30 and $35 \mathrm{~W}$ were similar $(P>0.05)$, except for $\mathrm{CF}$ $10-20 \mathrm{~g}$ for 20 to $40 \mathrm{~s}$, where power of $35 \mathrm{~W}$ provided significantly higher ID than $30 \mathrm{~W}(P<0.05)$.

The efficacy of HPSD ablation at $10 \mathrm{~s}$ was compared with the conventional sub-groups at different time points. ID $\geq 10$
$\Omega$ was achieved at $10 \mathrm{~s}$ in all cases with $\mathrm{CF} \geq 5 \mathrm{~g}$ in the HDSP group, but not $<5 \mathrm{~g}$. With CF $5-10 \mathrm{~g}$, ID in the HDSP group was higher than that under the setting of $25 \mathrm{~W}$ for $40 \mathrm{~s}$, and lower than under $30 \mathrm{~W}$ for $40 \mathrm{~s}$ and $35 \mathrm{~W}$ for $30 \mathrm{~s}$, respectively. With CF 10--20 g, ID in HDSP group was higher than that under $25 \mathrm{~W}$ for $30 \mathrm{~s}$ and lower than under $30 \mathrm{~W}$ for $40 \mathrm{~s}$ and $35 \mathrm{~W}$ for $30 \mathrm{~s}$, respectively. With $\mathrm{CF} \geq 20 \mathrm{~g}$, ID in the HDSP group was higher than that under $25 \mathrm{~W}$ for $10 \mathrm{~s}$, and lower than under both 30 and $35 \mathrm{~W}$ for $20 \mathrm{~s}$. Notably, differences of ID values at $10 \mathrm{~s}$ under powers of 30,35 and $50 \mathrm{~W}$ were not statistically significant.

The average of $\mathrm{AI}$ in the conventional group was higher than that in the HPSD group $(531.7 \pm 89.8$ vs. $395.8 \pm 43.1, P$ $<0.01)$. Higher AI was found in ablation applications with ID $\geq 10 \Omega$ than those with ID $<10 \Omega$ in both conventional (558.7 \pm 85.3 vs. $462.7 \pm 58.9, P<0.01)$ and HPSD groups $(405.7 \pm$ 43.3 vs. $380.1 \pm 37.9, P<0.01$ ), respectively.

The relationship between AI and ID under different power setting is presented in Fig. 2. The values of ID under various $\mathrm{AI}$ levels for powers of 30,35 and $50 \mathrm{~W}$ were similar and the corresponding curves of ID were uniformly superimposed, whereas $25 \mathrm{~W}$ resulted in significantly lower ID at all AI levels (for AI 350-500 W/g/s, $P<0.01$ ). Notably, a minimum of $450 \mathrm{~W} / \mathrm{g} / \mathrm{s}$ of AI was required to achieve ID of $10 \Omega$ under the power of $25 \mathrm{~W}$, while less than $350 \mathrm{~W} / \mathrm{g} / \mathrm{s}$ was sufficient to reach the same ID level under powers of 30-50 W.

\section{Discussion}

In this observational study, we evaluated the additive impacts of $\mathrm{CF}$, power and application time on the ablation efficacy based on ID level in patients undergoing AF ablation procedures in both conventional and HPSD settings. These three parameters compensated for each other in a CF ranging from 5 to $20 \mathrm{~g}$. However, with low $\mathrm{CF}(<5 \mathrm{~g})$, ID seldom reached the threshold of $10 \Omega$ even when power or application time was increased. The effect of HPSD ablation indicated by ID was equivalent to that of applying of $25 \mathrm{~W}$ for $40 \mathrm{~s}, 30 \mathrm{~W}$ for $30 \mathrm{~s}$ or $35 \mathrm{~W}$ for $20 \mathrm{~s}$. 
Fig. 1 Additive impacts of contact force, power and application time on impedance drop. With $\mathrm{CF}<5 \mathrm{~g}$, ID does not reach the threshold of $10 \Omega$ within $60 \mathrm{~s}$ at any power setting. When $\mathrm{CF} \geq 5 \mathrm{~g}$, power and application time compensate for each other within restricted ranges. Compared with the conventional sub-groups at different time points, ID levels at $10 \mathrm{~s}$ of HPSD ablation lie between those of the 25 and $30 \mathrm{~W}$ sub-groups under the same CF level. ID, impedance drop; CF, contact force; HPSD, high power short duration; $\uparrow P<$ 0.05 compared to $25 \mathrm{~W}, \ddagger P<$ 0.01 compared to $25 \mathrm{~W}, * P<$ 0.01 compared to $50 \mathrm{~W}$

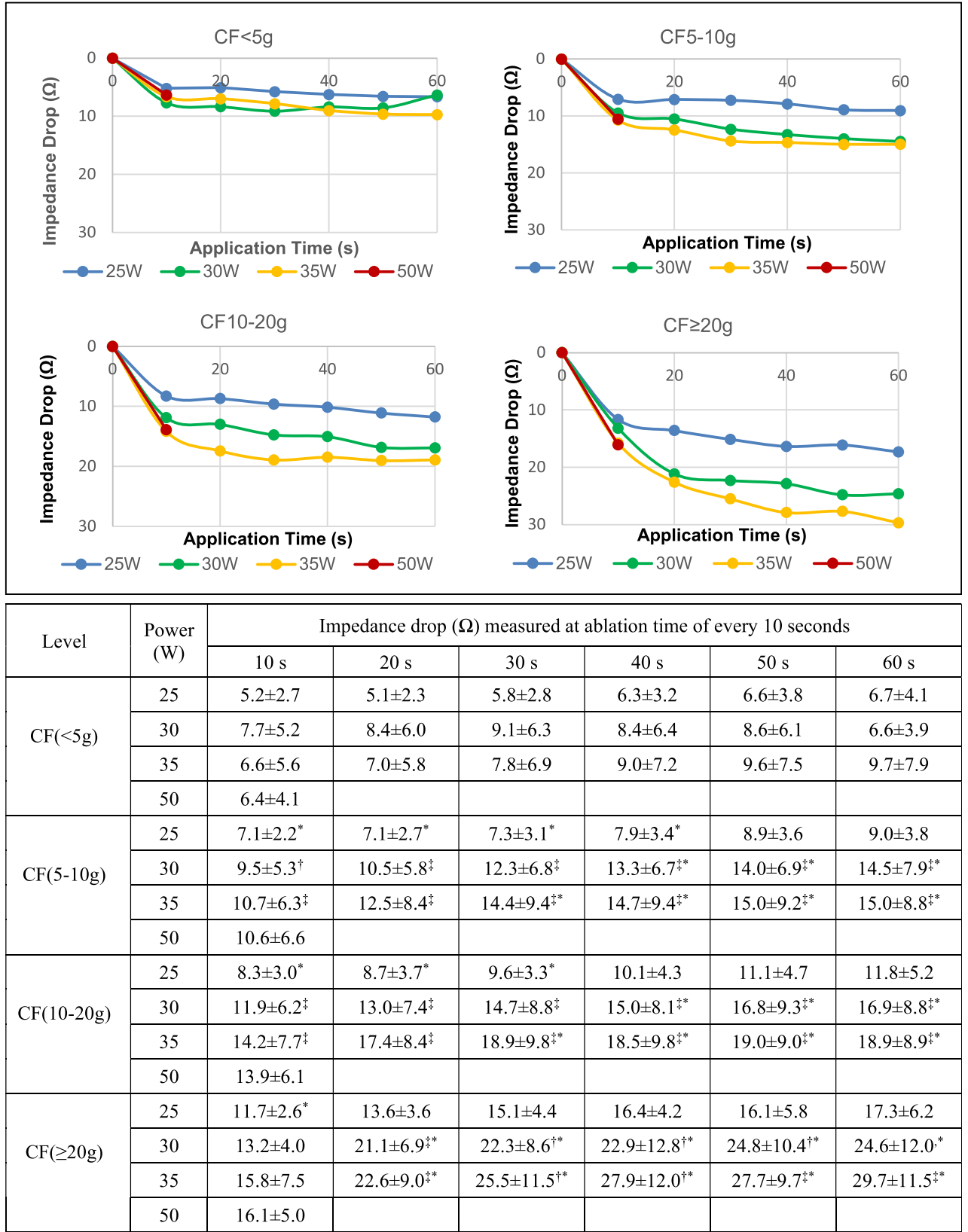

The essential role of $\mathrm{CF}$ in AF ablation has been demonstrated in a series of observational studies from basic to clinical level. However, no improvement of clinical outcomes with CF-sensing catheter was demonstrated in randomizedcontrolled trials $[4,18]$. Experimental models have shown how ablation efficacy is dependent on several parameters [9]. During RF ablation, the surface of tissue in contact with the ablation electrode is warmed immediately by the resistant heating, while the deeper tissue layer is warmed by the conductive heating at a later stage. Passively conductive heating is time-dependent [19]. Increasing current intensity or power output at the electrode-tissue interface produces higher temperature gradients and thus greater lesion size and depth. Impedance drop is often used as a surrogate for evaluating effect of ablation as supported by earlier animal and clinical investigations $[7,9,15,20,21]$, and previous studies have suggested an ID $\geq 10 \Omega$ to be a reliable indicator for an adequate lesion formation [16, 17, 22]. Avitall et al. demonstrated clearly on a dog model that impedance could slightly decrease $(0-10 \Omega)$ during RF delivery even when catheter tip was $5 \mathrm{~mm}$ away from the tissue surface and no lesion was created. Furthermore, they found that better contact led to higher ID, and both temperature increase and ID correlated with lesion diameter and depth when ID $>10 \Omega$ [15]. Ikeda et al. confirmed that the impedance drop during the RF application correlated well with lesion size [10]. Another clinical study conducted by Chinitz et al. showed that ID $<10 \Omega$ accounted for $89 \%$ of sites with conduction recovery and regions with 
Table 2 Time (in seconds) to reach impedance drop of $10 \Omega$ and to the maximal impedance drop (in parentheses)

\begin{tabular}{llllll}
\hline \multicolumn{7}{c}{ Mean contact force } \\
\cline { 2 - 6 } & & CF $<5 \mathrm{~g}$ & CF 5-10g & CF 10-20 g & CF $\geq 20 \mathrm{~g}$ \\
\hline Power & $25 \mathrm{~W}$ & - & - & $40(60)$ & $10(40)$ \\
& $30 \mathrm{~W}$ & - & $20(50)$ & $10(50)$ & $10(20)$ \\
& $35 \mathrm{~W}$ & - & $10(20)$ & $10(20)$ & $10(20)$ \\
& $50 \mathrm{~W}$ & - & $10^{\mathrm{a}}$ & $10^{\mathrm{a}}$ & $10^{\mathrm{a}}$ \\
\hline
\end{tabular}

$C F$ contact force

${ }^{\mathrm{a}}$ Total application time $10 \mathrm{~s}$

adjacent ablation with ID $<10 \Omega$ were associated with a higher rate of conduction recovery (37\% versus $1.5 \%$ ) [23].

Various studies reproducibly demonstrated that a maximum lesion volume is achieved after 30 to $40 \mathrm{~s}$ of energy delivery and the half-time of lesion growth is around $8 \mathrm{~s} \mathrm{[7,}$ 24]. In this study, the initial rapid fall of impedance was within $10 \mathrm{~s}$, and the time to reach the heating plateau was in line with earlier studies. Ablation settings with power of 25, 30 and $35 \mathrm{~W}$ for 20 to $60 \mathrm{~s}$ are widely used for AF ablation. In most cases with poor $\mathrm{CF}(<5 \mathrm{~g})$, neither increasing power output nor prolonging application time enhanced the ablation effect. This result is consistent with a previous study conducted in an ex vivo model [25]. However, the study conducted by Winkle et al. showed that $14.5 \%$ impedance drop was achieved by contact force $<5 \mathrm{~g}$ [26]. This observational difference might be explained by several reasons. Firstly, that study used the TactiCath $^{\mathrm{TM}}$ open irrigated-tip CF sensing catheter with EnSite $^{\text {TM }}$ Velocity ${ }^{\mathrm{TM}}$ system (St. Jude Medical). The methods of CF and impedance measurement are different from those employed in our study and the values of ID cannot be compared directly between two distinct systems. Secondly, the average application duration in that study was $12.5 \mathrm{~s}$, which was longer than ours. Our study showed that application time and power had an additional effect on ID as long as CF was at

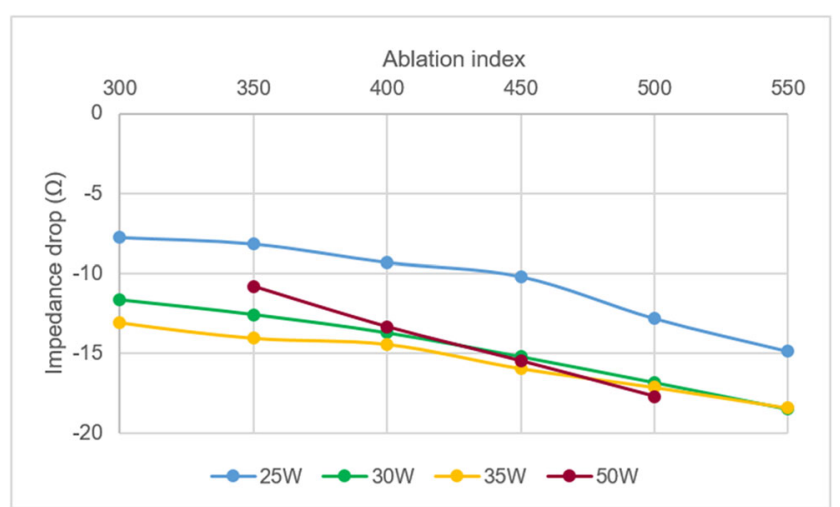

Fig. 2 Correlation between impedance drop and ablation index under different power settings. Changes of ID with increasing AI values are similar at settings of 30,35 and $50 \mathrm{~W}$. At $25 \mathrm{~W}$, they show the same trend, but with lower ID at the same AI level $(P<0.01)$ least $5 \mathrm{~g}$. While increase in power output resulted in consistently higher ID, the effect of increasing ablation time was insignificant after 30-40 s. This finding supports the idea of delivering RF energy to a target magnitude of AI rather than for a fixed duration. Outside this time window, the additional effect of prolonging application time on ID is limited, and indeed might lead to collateral tissue damage, especially with higher CF and power level.

Recently, more attention has been paid to the HPSD ablation strategy. Animal studies have shown the efficacy and safety of this strategy with several combinations of power (50 to $90 \mathrm{~W}$ ) and application time (4 to $8 \mathrm{~s}$ ) [27, 28]. Similar AF-freedom and complication rates of AF ablation using HPSD protocol with 45-50 W for 5-15 s compared with conventional strategy have been demonstrated by clinical studies [29, 30]. Bourier et al. reported that HPSD ablation, compared with standard RF application, resulted in similar lesion volumes, but with a larger maximum diameter and a smaller lesion depth. The lesion volume made by ablation using $50 \mathrm{~W}$ for $13 \mathrm{~s}$ was equal to that using $30 \mathrm{~W}$ for $30 \mathrm{~s}$ [25]. These findings were confirmed by our data which showed that ablation with $50 \mathrm{~W}$ for $10 \mathrm{~s}$ resulted in similar ID to the conventional $30 \mathrm{~W}$ for $30 \mathrm{~s}$. However, the ID was lower than that achieved using $30 \mathrm{~W}$ for $40 \mathrm{~s}$. Additionally, we found that a lower proportion of ablations achieved ID $\geq 10 \Omega$ in the HPSD than in the conventional group. This may be explained by a reduction of the conductive heating phase due to the shorter application duration in the HPSD ablation with power-controlled mode [27]. Thus, for the setting of $50 \mathrm{~W}$ and $10 \mathrm{~s}$, there might be advantage in titrated prolongation of ablation and cautious increasing of power to ensure durable lesion formation. Recently published data have shown new information supporting this hypothesis [31].

$\mathrm{AI}$ is a parameter integrating $\mathrm{CF}$, power and application time in a weighted formula. It has been reported that predicted lesion depth based on AI correlated well with actual lesion depth in the beating canine heart. It was noteworthy that the patterns of ID responding to AI were uniform under power outputs ranging from 30 to $50 \mathrm{~W}$, but not under $25 \mathrm{~W}$, a finding supported by results from a recent in vivo study. This observation could be explained by the fact that the customized formula for calculating AI was based on experiments that used power outputs of 30-50 W. The improvement of clinical outcomes and durability of AI-guided PV isolation has been reported in observational studies when target values of $550 \mathrm{~W} / \mathrm{g} / \mathrm{s}$ in the anterior and $400 \mathrm{~W} / \mathrm{g} / \mathrm{s}$ in the posterior left atrial regions were employed [32, 33]. Interestingly, our data showed that the AI of $350 \mathrm{~W} / \mathrm{g} / \mathrm{s}$ might be sufficient to reach the ID goal of $10 \Omega$ under powers of $30-50 \mathrm{~W}$.

Finally, CF, power and application time contribute individually to AI by different weight. According to our results, adequate $\mathrm{CF}$ is an essential prerequisite. Below the $\mathrm{CF}$ threshold of $5 \mathrm{~g}$, no significant enhancement of ablation effect can be 
made by increasing power or prolonging ablation time, even if total AI value has reached the recommended target value. On the other hand, with $\mathrm{CF} \geq 5 \mathrm{~g}$, the time to reach maximal ID can be reduced by increasing either $\mathrm{CF}$ or power. Our results showed that ablation effect could be simply enhanced about $33-88 \%, 49-100 \%$ and $125-227 \%$ by increasing application time from 10 to $60 \mathrm{~s}$, or power from 25 to $35 \mathrm{~W}$, or mean $\mathrm{CF}$ from 4.8 to $25.5 \mathrm{~g}$, respectively (Fig. 1). Our results suggested that optimizing CF should be the first step to enhance ablation effect, and followed by adjusting power or application time, while also considering the limit of effectiveness of time (after maxID) and the restriction of power in the locations for high risk of complications (the posterior wall and thoracic veins).

\subsection{Limitations}

This investigation was a single-centre non-randomized study. It focused on the effect of each single RF application without a mutual effect. Inevitably, the results could not be simply generalized to clinical outcomes. Impedance drop is a widely used parameter to monitor ablation effect but as a surrogate is flawed by several limitations as discussed previously $[34,35]$. Also, impedance is measured in clinical practice with different techniques. This may influence the interpretation of optimal ID for an adequate lesion. Few points with high $\mathrm{CF}$ were involved in this study as catheter stability was more challenging in such situations without the support of a steerable long sheath. The ablation effect with steerable sheath may need further investigations. Power settings were selected following clinical practice, and therefore, no further information on other power levels was available. No analyses of complications with increasing $\mathrm{CF}$, power and application time were performed because of extremely low incidence under the current settings.

\section{Conclusions}

$\mathrm{CF}$ of at least $5 \mathrm{~g}$ is required for effective ablation. With $\mathrm{CF} \geq 5$ $\mathrm{g}, \mathrm{CF}$, power and application time can compensate for each other within restricted ranges. Time to reach maximal ablation effect can be shortened by increasing CF or power output. The effect of HPSD ablation with $50 \mathrm{~W}$ for $10 \mathrm{~s}$ is equivalent to conventional ablation with $25 \mathrm{~W}$ for $40 \mathrm{~s}$ and $30-35 \mathrm{~W}$ for $20-30 \mathrm{~s}$ in terms of ID. The ID versus AI increase matches well at power outputs between 30 and $50 \mathrm{~W}$, but with lower ID values at $25 \mathrm{~W}$.

Funding Open access funding provided by University of Bergen (incl Haukeland University Hospital). This study was partly supported by Helse Vest, Norway and the Research Council of Norway.

\section{Declarations}

Conflict of interest The authors declare no competing interests.

Open Access This article is licensed under a Creative Commons Attribution 4.0 International License, which permits use, sharing, adaptation, distribution and reproduction in any medium or format, as long as you give appropriate credit to the original author(s) and the source, provide a link to the Creative Commons licence, and indicate if changes were made. The images or other third party material in this article are included in the article's Creative Commons licence, unless indicated otherwise in a credit line to the material. If material is not included in the article's Creative Commons licence and your intended use is not permitted by statutory regulation or exceeds the permitted use, you will need to obtain permission directly from the copyright holder. To view a copy of this licence, visit http://creativecommons.org/licenses/by/4.0/.

\section{References}

1. Haissaguerre M, Jais P, Shah DC, Takahashi A, Hocini M, Quiniou $\mathrm{G}$, et al. Spontaneous initiation of atrial fibrillation by ectopic beats originating in the pulmonary veins. N Engl J Med. 1998;339:65966.

2. Kuck KH, Hoffmann BA, Ernst S, Wegscheider K, Treszl A, Metzner A, et al. Impact of complete versus incomplete circumferential lines around the pulmonary veins during catheter ablation of paroxysmal atrial fibrillation: results from the Gap-Atrial Fibrillation-German Atrial Fibrillation Competence Network 1 Trial. Circ Arrhythm Electrophysiol. 2016;9:e003337.

3. Verma A, Jiang CY, Betts TR, Chen J, Deisenhofer I, Mantovan R, et al. Approaches to catheter ablation for persistent atrial fibrillation. N Engl J Med. 2015;372:1812-22.

4. Ullah W, McLean A, Tayebjee MH, Gupta D, Ginks MR, Haywood GA, et al. Randomized trial comparing pulmonary vein isolation using the SmartTouch catheter with or without real-time contact force data. Heart Rhythm. 2016;13:1761-7.

5. Das M, Wynn GJ, Saeed Y, Gomes S, Morgan M, Ronayne C, et al. Pulmonary vein re-Isolation as a routine strategy regardless of symptoms: The PRESSURE randomized controlled trial. JACC Clinical electrophysiology. 2017;3:602-11.

6. Kautzner J, Neuzil P, Lambert H, Peichl P, Petru J, Cihak R, et al. EFFICAS II: optimization of catheter contact force improves outcome of pulmonary vein isolation for paroxysmal atrial fibrillation. Europace. 2015;17:1229-35.

7. Eick OJ, Gerritse B, Schumacher B. Popping phenomena in temperature-controlled radiofrequency ablation: when and why do they occur? PACE. 2000;23:253-8.

8. He DS, Bosnos M, Mays MZ, Marcus F. Assessment of myocardial lesion size during in vitro radio frequency catheter ablation. IEEE Trans Biomed Eng. 2003;50:768-76.

9. Thiagalingam A, D'Avila A, Foley L, Guerrero JL, Lambert H, Leo $\mathrm{G}$, et al. Importance of catheter contact force during irrigated radiofrequency ablation: evaluation in a porcine ex vivo model using a force-sensing catheter. J Cardiovasc Electrophysiol. 2010;21:806-11.

10. Ikeda A, Nakagawa H, Lambert H, Shah DC, Fonck E, Yulzari A, et al. Relationship between catheter contact force and radiofrequency lesion size and incidence of steam pop in the beating canine heart: electrogram amplitude, impedance, and electrode temperature are poor predictors of electrode-tissue contact force and lesion size. Circ Arrhythm Electrophysiol. 2014;7:1174-80. 
11. Virk SA, Ariyaratnam J, Bennett RG, Kumar S. Updated systematic review and meta-analysis of the impact of contact force sensing on the safety and efficacy of atrial fibrillation ablation: discrepancy between observational studies and randomized control trial data. Europace. 2019;21:239-49.

12. Solheim E, Off MK, Hoff PI, De Bortoli A, Schuster P, Ohm OJ, et al. N-terminal pro-B-type natriuretic peptide level at long-term follow-up after atrial fibrillation ablation: a marker of reverse atrial remodelling and successful ablation. J Interv Card Electrophysiol. 2012;34:129-36.

13. De Bortoli A, Sun LZ, Solheim E, Hoff PI, Schuster P, Ohm OJ, et al. Ablation effect indicated by impedance fall is correlated with contact force level during ablation for atrial fibrillation. J Cardiovasc Electrophysiol. 2013;24:1210-5.

14. Nakagawa H, Ikeda A, Govari A, Papaioannou T, Constantine G, Bar-Tal M, et al. Prospective study using a new formula Incorporating contact force, radiofrequency power and application time (Force-Power-Time Index) for quantifying lesion formation to guide long continuous atrial lesions in the beating canine heart. Circulation. 2013;128.

15. Avitall B, Mughal K, Hare J, Helms R, Krum D. The effects of electrode-tissue contact on radiofrequency lesion generation. Pace. 1997;20:2899-910.

16. Nsah E, Berger R, Rosenthal L, Hui R, Ramza B, Jumrussirikul P, et al. Relation between impedance and electrode temperature during radiofrequency catheter ablation of accessory pathways and atrioventricular nodal reentrant tachycardia. Am Heart J. 1998;136:84451.

17. Harvey M, Kim YN, Sousa J, el-Atassi R, Morady F, Calkins H, et al. Impedance monitoring during radiofrequency catheter ablation in humans. PACE. 1992;15:22-7.

18. Pedrote A, Arana-Rueda E, Arce-Leon A, Acosta J, Gomez-Pulido F, Martos-Maine JL, et al. Impact of contact force monitoring in acute pulmonary vein Isolation using an anatomic approach. A randomized study. PACE. 2016;39:361-9.

19. Huang SK, Graham AR, Lee MA, Ring ME, Gorman GD, Schiffman R. Comparison of catheter ablation using radiofrequency versus direct current energy: biophysical, electrophysiologic and pathologic observations. JACC. 1991;18:1091-7.

20. Ullah W, Hunter RJ, Baker V, Dhinoja MB, Sporton S, Earley MJ, et al. Target indices for clinical ablation in atrial fibrillation: insights from contact force, electrogram, and biophysical parameter analysis. Circ Arrhythm Electrophysiol. 2014;7:63-8.

21. Anter E, Tschabrunn CM, Contreras-Valdes FM, Buxton AE, Josephson ME. Radiofrequency ablation annotation algorithm reduces the incidence of linear gaps and reconnection after pulmonary vein isolation. Heart Rhythm. 2014;11:783-90.

22. Thiagalingam A, D'Avila A, McPherson C, Malchano Z, Ruskin J, Reddy VY. Impedance and temperature monitoring improve the safety of closed-loop irrigated-tip radiofrequency ablation. J Cardiovasc Electrophysiol. 2007;18:318-25.

23. Chinitz JS, Kapur S, Barbhaiya C, Kumar S, John R, Epstein LM, et al. Sites with small impedance decrease during catheter ablation for atrial fibrillation are associated with recovery of pulmonary vein conduction. J Cardiovasc Electrophysiol. 2016;27:1390-8.
24. Wittkampf FH, Hauer RN. Robles de Medina EO. Control of radiofrequency lesion size by power regulation. Circulation. 1989;80: 962-8.

25. Bourier F, Duchateau J, Vlachos K, Lam A, Martin CA, Takigawa $\mathrm{M}$, et al. High-power short-duration versus standard radiofrequency ablation: Insights on lesion metrics. J Cardiovasc Electrophysiol. 2018;29:1570-5.

26. Winkle RA, Moskovitz R, Hardwin Mead R, Engel G, Kong MH, Fleming W, et al. Atrial fibrillation ablation using very short duration $50 \mathrm{~W}$ ablations and contact force sensing catheters. J Interv Card Electrophysiol. 2018;52:1-8.

27. Bhaskaran A, Chik W, Pouliopoulos J, Nalliah C, Qian P, Barry T, et al. Five seconds of 50-60 W radio frequency atrial ablations were transmural and safe: an in vitro mechanistic assessment and forcecontrolled in vivo validation. Europace. 2017;19:874-80.

28. Leshem E, Zilberman I, Tschabrunn CM, Barkagan M, ContrerasValdes FM, Govari A, et al. High-power and short-duration ablation for pulmonary vein Isolation: biophysical characterization. JACC Clinical electrophysiology. 2018;4:467-79.

29. Baher A, Kheirkhahan M, Rechenmacher SJ, Marashly Q, Kholmovski EG, Siebermair J, et al. High-power radiofrequency catheter ablation of atrial fibrillation: using late gadolinium enhancement magnetic resonance imaging as a novel index of esophageal Injury. JACC Clin Electrophysiol. 2018;4:1583-94.

30. Winkle RA, Mohanty S, Patrawala RA, Mead RH, Kong MH, Engel $\mathrm{G}$, et al. Low complication rates using high power (45-50 W) for short duration for atrial fibrillation ablations. Heart Rhythm. 2019;16:165-9.

31. Kottmaier M, Popa M, Bourier F, Reents T, Cifuentes J, Semmler $\mathrm{V}$, et al. Safety and outcome of very high-power short-duration ablation using $70 \mathrm{~W}$ for pulmonary vein isolation in patients with paroxysmal atrial fibrillation. Europace. 2020;22:388-93.

32. Phlips T, Taghji P, El Haddad M, Wolf M, Knecht S, Vandekerckhove Y, et al. Improving procedural and one-year outcome after contact force-guided pulmonary vein isolation: the role of interlesion distance, ablation index, and contact force variability in the 'CLOSE'-protocol. Europace. 2018;20:f419-27.

33. Hussein A, Das M, Riva S, Morgan M, Ronayne C, Sahni A, et al. Use of ablation index-guided ablation results in high rates of rurable pulmonary vein isolation and freedom from arrhythmia in persistent atrial fibrillation patients. Circ Arrhythm Electrophysiol. 2018;11: e006576.

34. Squara F, Latcu DG, Massaad Y, Mahjoub M, Bun SS, Saoudi N. Contact force and force-time integral in atrial radiofrequency ablation predict transmurality of lesions. Europace. 2014;16:660-7.

35. Wright MHE, Deladi S, Suijver F, Barley M, van Dusschoten A, et al. Real-time lesion assessment using a novel combined ultrasound and radiofrequency ablation catheter. Heart Rhythm. 2011;8:9.

Publisher's note Springer Nature remains neutral with regard to jurisdictional claims in published maps and institutional affiliations. 